Cuadernos de Filología Clásica. Estudios Latinos

ISSN: 1131-9062

https://dx.doi.org/10.5209/cfcl.77310

\title{
Exempla loquuntur: la función política de los ejemplos en la obra retórica de Fadrique Furio Ceriol ${ }^{1}$
}

\author{
Concepción Ferragut Domínguez ${ }^{2}$
}

Recibido: 15 de septiembre de 2020 / Aceptado: 28 de mayo de 2021

Resumen. El manual del humanista valenciano Fadrique Furio Ceriol Institutionum Rhetoricarum libri tres (Lovaina, 1554) presenta abundante material de ejemplificación para ilustrar su teoría retórica, con un volumen que supera los 500 ejemplos (entendido el término 'ejemplo' en su acepción de 'texto o cláusula que se cita para comprobar, ilustrar o autorizar un aserto', no en la referente al concepto de exemplum retórico 'caso o hecho sucedido en otro tiempo, que se propone, o bien para que se imite y siga, si es bueno y honesto, o para que se evite si es malo'). Para demostrar que el humanista valenciano emplea dichos ejemplos no solo con una función ilustrativa de la preceptiva retórica, sino también como un recurso ideológico destacado en el marco de un proyecto político global, en el presente trabajo realizamos el estudio de estos intertextos clasificándolos según su tipología, extensión y temática para después, centrándonos en su contenido, analizar su elección y manipulación por parte de Furio en relación con las cualidades necesarias en el hombre de Estado para la consecución del bien común expuestas en su tratado de ciencia política El Concejo, i Consejeros del Príncipe (Amberes, 1559).

Palabras clave: Retórica siglo XVI; Humanismo español; Fadrique Furio Ceriol; Intertextos de ejemplificación.

\section{[en] Exempla Loquuntur: the political role of examples in the rhetorical work of Fadrique Furio Ceriol}

\begin{abstract}
The manual of Valencian humanist Fadrique Furio Ceriol Institutionum Rhetoricarum libri tres (Louvain, 1554) presents abundant material of exemplification to illustrate his rhetorical theory, with a volume that exceeds 500 examples (the term 'example' understood in its sense of 'text or clause that is quoted to verify, illustrate or authorize an assertion', not in reference to the concept of rhetorical exemplum 'case or event that happened in another time, which is proposed, either to be imitated and followed, if it is good and honest, or to be avoided if it is bad'). To demonstrate that the Valencian humanist uses these examples not only with an illustrative function of the prescriptive rhetoric, but also as a prominent ideological resource in the framework of a global political project, in the present work we study these intertexts classifying them according to their typology, extension and topic and then, focusing on their content, we analyze the choice and manipulation by Furio in relation to the necessary qualities in the statesman as exposed in his political science treatise El Concejo, i Consejeros del Príncipe (Antwerp, 1559).
\end{abstract}

Keywords: XVIth Century Rhetoric; Spanish Humanism; Fadrique Furio Ceriol; Exemplification Intertexts.

1 Proyecto de investigación Memoria, Imagen y Conflicto en el arte y la arquitectura del Renacimiento: La Revuelta de las Germanías de Valencia (HAR2017-88707-P).

2 Universitat de València-Estudi General. Correo electrónico: concepcion.ferragut@uv.es. 
Sumario. 1. Introducción. 2. Los Institutionum Rhetoricarum libri tres. 3. El Concejo, i Consejeros del Príncipe. 4. Los ejemplos de los Institutionum Rhetoricarum libri tres. 5. Las cualidades del consejero reflejadas en los ejemplos de Institutionum Rhetoricarum libri tres. 6. Conclusiones.

Cómo citar: Ferragut Domínguez, C. «Exempla loquuntur: la función política de los ejemplos en la obra retórica de Fadrique Furio Ceriol», Cuad. Filol. Clás. Estud. Lat. 41.1 (2021), 97-121.

\section{Introducción}

El humanista valenciano Fadrique Furio ${ }^{3}$ Ceriol publicó entre 1554 y 1559 cuatro obras de temática muy diferente: el manual de retórica Institutionum Rhetoricarum libri tres (Lovaina, 1554), el tratado teológico Bononia, siue de libris sacris in uernaculam linguam conuertendis, libri duo (Basilea, 1556), en el que defiende la traducción de la Biblia, el tratado de ciencia política El Concejo, $i$ Consejeros del Príncipe (Amberes, 1559), que expone el modelo de estadista ideal a través de las cualidades del buen consejero, y la Gramatica de la Lengua Vulgar de España (Lovaina, 1559), que defiende una preceptiva peculiar y claramente diferenciada de la de las gramáticas del momento ${ }^{4}$. A pesar de la aparente dispersión temática, la obra impresa de Furio conforma un corpus unitario cuyo hilo conductor es el constante equilibrio entre teoría y práctica, pues Furio establece a través de sus muy personales manuales de retórica y de gramática el marco teórico para exponer el pensamiento desarrollado en sus escritos teológicos y políticos: por un lado, la Gramatica parece haber sido planificada para dar carta de naturaleza al peculiar usus escriturario de El Concejo, $i$ Consejeros del Príncipe $e^{5}$ donde se aplican fiel y sistemáticamente todas las particularidades ortográficas exclusivas de la Gramatica-; por otro, la teoría retórica de los Institutionum Rhetoricarum libri tres (en adelante $I R$ ) constituye el soporte estructural y formal tanto de Bononia (Grau 2000 y García Pinilla 2003), como de El Concejo, $i$ Consejeros del Príncipe (en adelante EC), donde Furio aplica con precisión su preceptiva retórica construyendo la dispositio del tratado político sobre el orden de los argumentos y la colocación de las figuras, ejes de su ars rhetorica (Ferragut-Grau 2016, 57-92 y Ferragut 2019), testimoniando aún más, si cabe, la unión indisoluble entre retórica y sociedad defendida siempre por nuestro autor (IR 108).

Puede entenderse como otra manifestación del equilibrio entre el pensamiento de Furio y su expresión práctica el hecho de que el modelo teórico de consejero propuesto en EC cristaliza en el propio Furio, que en su Petición a Felipe II del cargo de vicecanciller de Aragón declara poseer las cualidades necesarias para convertirse en el perfecto consejero (Ferragut en prensa).

Por otra parte, los escritos de Furio están vinculados entre sí por una lógica interna y una coherencia ideológica y personal profundas ${ }^{6}$. Los lazos ideológicos entre

\footnotetext{
Sobre las razones por las que transcribimos Furio, y no Furió, cf. Ferragut-Grau (2016, 39 nota 1).

4 Especialmente el libro I, dedicado a la ortografía, que presenta unas particularidades ortográficas exclusivas. La Gramatica ha sido tradicionalmente considerada anónima, pero, como creemos haber demostrado (AlmenaraFerragut-Grau 2021) apoyándonos en argumentos ortográficos, retóricos, de estilo, literarios e ideológicos, debe atribuirse a Furio.

5 Que también puede verse en su obra manuscrita, como, por citar un ejemplo, la Petición a Felipe II (7 de octubre de 1581).

${ }^{6} \quad$ Los años comprendidos entre la publicación de $I R$ y $E C$ constituyeron para Furio un periodo agitado desde el punto de vista personal. A raíz de la publicación de Bononia fue considerado sospechoso de herejía e inves-
} 
$I R$ y Bononia han sido estudiados por Grau (2000) y Ferragut-Teodoro (2016). En el caso de $I R$ y $E C$, desde que D'Ascia $(1999,569)$ definió $I R$ como «una retorica dell'ordine e della prudenza -non del mero praeceptum-, antiformalistica e proiettata sulla vita civile», es acuerdo común que la obra cumple una función prologal del ideario político de Furio.

En el marco de dicha función prologal, en estas páginas nos planteamos en qué medida el material ejemplificativo de $I R$ puede haber sido seleccionado, además de por su misión ilustrativa de la teoría retórica, por su contribución al mensaje ideológico de $E C$, que entiende la elocuencia como una herramienta al servicio de la sociedad, defiende la meritocracia y propugna un modelo de hombre de Estado con vocación de servicio, profesionalizado y laico.

\section{Los Institutionum Rhetoricarum libri tres}

El tratado es una obra no muy conocida, pero sí peculiar y original en sus postulados si se compara con las retóricas que en el siglo XVI circulaban por España y Europa, originalidad y fuerza innovadora que desde la última década del siglo $\mathrm{XX}$ ya han sido evidenciadas en diferentes ocasiones ${ }^{7}$.

Es también reconocido por los especialistas que la inspiración principal de Furio son las teorías de Petrus Ramus y Omer Talon expuestas en los Institutionum Dialecticarum libri tres de Ramus, con comentarios de Talon, y en las Institutiones Oratoriae y la Rhetorica, publicadas a nombre de Talon, que atribuyen a la dialéctica el estudio de inuentio, dispositio y memoria, y asignan a la retórica el de la elocutio y la pronuntiatio. El valenciano también asigna dos partes a la retórica, y coincide con los anteriores en que la primera de ellas ha de ser la elocutio, a la que dedica el L. I, pero elimina del esquema la pronuntiatio e introduce en su lugar una segunda parte denominada dispositio rhetorica. Furio desarrolla la dispositio en el L. II y la articula sobre tres puntos: partes del discurso (incluidas tradicionalmente en la inuentio) - colocación de los argumentos y su amplificación - colocación de las figuras ${ }^{8}$.

tigado por orden de Felipe II, siendo encarcelado en dos ocasiones (Méchoulan-Almenara 1996, 22-23, 26; Ferragut-Grau 2016, 39-48, especialmente p. 47). Finalmente, en 1562 Furio alcanzó un acuerdo en virtud del cual, a cambio de no publicar las partes de $E C$ pendientes de edición, recibiría una pensión real, dedicándose desde entonces a tareas diplomáticas al servicio de la Corona y reclamando hasta el final de sus días un cargo en la Corte a la altura de sus capacidades y merecimientos.

7 Por citar algunos ejemplos, Puerta $(1993,851$ y 1997, 469) la califica de singular, e incluso atrevida en aspectos como su exposición en el campo de las figuras de dicción, que incluye los tropos como figurae in uerbis coniunctis, frente a las preceptivas de la tradición clásica y de sus maestros contemporáneos. Otro tanto hace Luján (1999, 213-250) que incide en su desvinculación total de la elocución oratoria con la gramática, y destaca su concepción de la retórica como una retórica del discurso científico. Lorenzo (2003, 194-195, 197; 209) califica de excepcional y singular la propia definición de retórica de Furio y destaca su defensa de la aplicación de los preceptos retóricos a la literatura. Truman $(2009,382)$ realza el enfoque independiente que el humanista valenciano da a la materia.

8 Entre los estudiosos del ramismo de Furio, algunos autores inciden en los aspectos que separan la concepción retórica de Ramus y la de Furio (Merino 1992, 123-126, 226; Martín 1997, 15-16; Puerta 1998, 134; Luján 1998, 1397; D’Ascia 1999, 560-561), mientras que otros ponen el acento en las similitudes, como Truman (2009), que destaca la proximidad doctrinal y de actitudes entre Ramus y Furio; o, más recientemente, Grau (en prensa), para quien Ramus es, por lo que respecta a la configuración de $I R$, el único interlocutor de Furio, el cual pretende completar con su preceptiva el sistema retórico ideado por Ramus y Talon. 
Furio nunca se dedicó a la docencia; en cambio, desarrolló una intensa actividad diplomática al servicio de la Corona y se mantuvo siempre en contacto con la realidad política y militar contemporánea, por lo que tal vez este manual fuera concebido no tanto para su explicación en las aulas como para la formación de jóvenes intelectuales con inquietudes políticas, mediante la enseñanza de unas reglas generales, claras y simples para la expresión del pensamiento, cualquiera que fuera la forma literaria adoptada.

El manual abunda en reflexiones que ponen de manifiesto el pensamiento que Furio desarrollará ampliamente en su obra posterior y que podemos resumir así: el ars rhetorica no es sino el desarrollo de la capacidad natural de expresarse, conducente al dominio de la palabra y, por tanto, al diálogo, que es el medio de expresión de la razón y patrimonio universal sin exclusión de raza, edad o nacimiento. La retórica, por tanto, adquiere un profundo sentido social, una utilidad cívica, y su objetivo último es el bien común, con el cual Furio se siente profundamente comprometido?

\section{El Concejo, i Consejeros del Príncipe}

Esta obra es un tratado o, más exactamente, parte de un amplio y complejo tratado de ciencia política dedicado a Felipe II, cuyo objetivo más explícito es enseñar al gobernante cómo se debe organizar el aparato del Estado ${ }^{10}$, cuáles son las competencias y cualidades físicas, intelectuales y morales de sus consejeros y cómo estos deben ser elegidos ${ }^{11}$. La obra sigue la estela de Maquiavelo, especialmente de los Discursos sobre la primera década de Tito Livio y El Príncipe, aunque no dejan de existir diferencias doctrinales entre ambos (Hermosa (2010, 24-26).

Furio defiende en esta obra un ideario basado en la separación entre poder religioso y poder político, la profesionalización de los cargos políticos y el acceso a los mismos a través de los propios méritos con la única finalidad de conseguir el bien común, objetivo al que tanto el gobernante como el ciudadano particular tienen el compromiso de contribuir. Desarrolla estas ideas a través de las veinte cualidades que debe poseer un buen hombre de Estado, quince relativas al alma y cinco al cuerpo (Ferragut-Teodoro 2016, 319; Álvarez 2016, 665-666, 679). Con respecto a las del alma, las que nos interesan aquí, las ocho primeras podrían agruparse en cualidades de carácter intelectual, o político-intelectual y vendrían a ser como una especie de desglose de los diferentes requisitos que, partiendo de un talento natural, conducen a la sabiduría. Las otras siete son más bien de carácter moral y, como indica Requesens $(2009,122-123)$, se corresponderían con la noción general de virtud, es decir, la disposición del individuo para obrar, independientemente de los preceptos de la ley, por la sola bondad de la operación y de conformidad con la ley natural ${ }^{12}$. Dichas cualidades son las siguientes: 1. inteligencia superior; 2. elocuencia; 3. poliglosia;

$9 \quad C f$. su defensa de las letras en el prólogo de la obra (IR II-VIII), donde Furio reflexiona sobre la naturaleza del poder, la tiranía y la función social y política de la retórica.

10 En la concepción de la obra reside también un innegable propósito de promoción personal.

11 En realidad, fue este capítulo el único que llegó a publicarse. Sobre la posibilidad de que la obra estuviera concebida como un libro independiente y no como parte de un tratado más amplio, $c f$. Ferragut-Grau (2016, 55-57); Ferragut (en prensa).

12 Méchoulan-Almenara (1996, 59 y nota 61) recalcan el carácter laico y político de las cualidades, rechazando cualquier vinculación con las virtudes cardinales del cristianismo, como defienden otros autores. 
4. conocimiento de la Historia; 5. dotes de psicología; 6. conocimiento de estrategia político-militar interior y exterior; 7. cosmopolitismo; 8. sentido de Estado; 9. espíritu de sacrificio; 10. imparcialidad; 11. justicia; 12. generosidad; 13. espíritu de servicio; 14. afabilidad, 15. amor por la verdad y fortaleza de espíritu.

\section{Los ejemplos de los Institutionum Rhetoricarum libri tres}

Si bien el tema que tratamos aquí es el de los ejemplos utilizados en el manual de retórica de Furio, nuestro trabajo no debe entenderse como un estudio sobre el exemplum retórico, es decir, sobre el ejemplo en la acepción de 'hecho fijado histórico (mitológica o literariamente), que es puesto en comparación con el pensamiento propiamente dicho' (Lausberg 1975, $204 \S 404$ ), sino sobre los ejemplos entendidos en su acepción de 'texto o cláusula que se cita para comprobar, ilustrar o autorizar un aserto' (Real Academia Española s.f. definición 3), es decir, sobre los intertextos de carácter ilustrativo que Furio emplea a lo largo del manual para explicar su preceptiva. De hecho, como veremos a continuación, el valenciano no se ocupa del exemplum retórico.

En el ámbito de la preceptiva retórica clásica, los exempla constituyen, junto con los argumentos, tipos de prueba artificial; los testimonia, por su parte, son un tipo de prueba inartificial (Qvint.inst.5.1.1, 5.7 y 5.9.1); todos ellos son considerados recursos adecuados para la persuasión (Cic.Part.14.49; Qvint.inst.5.11.6). Como recuerda Harto (2011) en su recorrido por la evolución del exemplum retórico desde la Antigüedad al Renacimiento, su función persuasiva y de educación cívica no se pierde durante la Edad Media, aunque cambia el marco, las fuentes y los destinatarios, y su finalidad pasa a ser esencialmente religiosa. En los siglos XV y XVI el exemplum recupera los parámetros clásicos, incorpora como receptores a lectores y a los jóvenes en las aulas y «aparece nuevamente en las retóricas y en la obra de humanistas que aconsejan su utilización [...] pues encierra cualidades como brevedad, claridad y verosimilitud, que son muy apreciadas en cualquier texto renacentista» (Harto 2011, 515).

Entre las retóricas renacentistas, a diferencia de las que siguen la corriente grecolatina tradicional, las retóricas elocutivas suelen omitir el tratamiento del exemplum y del testimonium juntamente con el de los argumentos, pues todos ellos son materia de la dialéctica ${ }^{13}$. Furio no es una excepción y, siguiendo a Ramus en su simplificación de la preceptiva, también los excluye, pero admite que el orador debe conocerlos y familiarizarse con su uso para poder dominar todas las formas de argumentos que se le objeten y poder defender o refutar, por lo que busca un punto medio y, reconociendo su gran fuerza probatoria, los menciona brevemente en un apéndice al final del L. II (IR 206-207).

Centrándonos ya en los intertextos de ejemplificación, Furio, que explicita su utilidad en varios lugares de la obra (IR 124-125, 130, 170, 261), los emplea en abundancia. En nuestro análisis de los ejemplos hemos contabilizado un total de 531: 228 en el L. I, 133 en el L. II y 170 en el L. III, y los hemos clasificado en función de su tipología, extensión y tema.

13 Puede encontrarse una visión completa de la abundante y variada preceptiva ejemplar de los diferentes tratados de retórica del siglo XVI en Aragüés (1993 y 1997) y Harto (2011). Sobre las retóricas elocutivas hispanas, $c f$. Martín (1997, 7-15, 29-30, 36-39), Núñez (2002, 678-684) y Lorenzo (2003, 198-204). 


\section{1) Tipología}

1.1) Cita directa o textual:

1.1.a) Identificada ${ }^{14}$. Indica el nombre del autor y, normalmente, la obra:

Epizeuxis est in eadem ambitus parte uerbi eiusdem aut geminatio aut, post breuissimam interpositionem, repetitio. Geminatio est illa Ciceronis Pro Cluentio (Cic. Cluent.65): "Audete negare ab Oppianico, Staleno iudici pecuniam datam, negate, negate, inquam, in eo loco" (IR 46).

1.1.b) Anónima ${ }^{15}$. Se trata generalmente de proverbios, máximas, sentencias: $A b$ odoratu etiam ducuntur [translationes], ut "olet lucernam", "olet mendacium”, olet malitiam" (IR 33).

1.2) Cita indirecta:

1.2.a) Paráfrasis ${ }^{16}$. Explica o resume el texto identificando al autor, pero no lo cita literalmente:

Communicatione utitur Cicero in respondendo, idque ita ut sumpto eo quod sibi obiiciebatur mistoque cum ratione quae dissoluat quaestionem, utrisque coniunctis solet communicare cum aduersario et quid sibi in tali re faciendum putet sententiam rogat. Veluti Pro Murena (Cic.Mur.3), cum a Catone accusaretur, quod talem uirum defenderet, rationem hanc Cicero reddit, aequum esse a consule defendi consulem, et neminem debere sibi habere coniunctiorem quam eum, cui Rempublicam sustinendam tradidisset (IR 190).

1.2.b) Referencia ${ }^{17}$. Alude a un autor o a una obra concretos sin aportar texto: In controuersiis nemo non uidet quam sit utilis haec narratio, uel ad accusandum uel defendendum. Sic Cicero In Verrem narrat atque describit nobilem ciuitatem Syracusas, ut adaugeat crimina, furta, scelera C. Verris (IR 123).

\section{2) Extensión}

2.1) Muy breves ${ }^{18}$. Constan de una palabra o un sintagma: Ducuntur interdum a nationibus huiusmodi nomina, ut a Corintio "corinthissare", a Care "caryssare", a Creta "cretissare". Plautus (Plavt.Men.12) dixit "siculitissare" pro eo quod est astute loqui et aliud in pectore clausum, aliud in ore gestare (IR 11).

2.2) Breves $^{19}$. No superan las 40 palabras (2-5 líneas): Porro autem proponendi formae duae esse possunt, una breuissima, qualis est illa Ciceronis Pro P. Quinctio

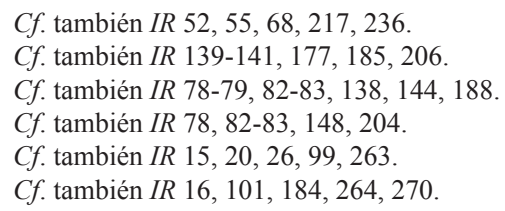


(Cic. Quinct.36): “Negamus te bona P. Quinctii, Sexte Naeui, possedisse ex edicto praetoris” (IR 127).

2.3) Intermedios ${ }^{20}$. Los forman párrafos de 40 a 70 palabras (4-10 líneas):

Tertio modo, ad recreandos auditorum animos, in quem allegoriae solent incidere, et habet multum luminis oratio, quale est illud Ciceronis In Pisonem (Cic.Pis.2021): "Neque tam fui timidus, ut qui maximis turbinibus ac fluctibus Reipublicae nauem gubernassem, saluamque in portu collocassem, frontis tuae nubeculam, tum collegae tui contaminatum spiritum pertimescerem; alios ego uidi uentos, alias prospexi animo procellas, aliis impendentibus procellis non cessi, sed unum me pro omnium salute obtuli" (IR 174).

2.4) $\operatorname{Largos}^{21}$. Párrafos de entre 70 y 150 palabras (10-25 líneas):

Proponendi altera forma ex pluribus constat uerbis; huiuscemodi est illa Ciceronis Pro lege Manilia (Cic.Manil.4): "Atque ut inde oratio mea proficiscatur unde haec omnis causa ducitur, bellum graue et periculosum uestris uectigalibus atque sociis a duobus potentissimis regibus infertur, Mithridate et Tigrane, quorum alter relictus, alter lacessitus, occasionem sibi ad occupandam Asiam oblatam esse arbitratur. Equitibus Romanis honestissimis uiris afferuntur ex Asia quotidie literae, quorum magnae res aguntur in uestris uectigalibus exercendis occupatae; qui ad me, pro necessitudine quae mihi est cum illo ordine, causam reipublicae periculumque rerum suarum detulerunt, Bithyniae, quae nunc uestra prouincia est, uiros exustos esse complures; regnum Ariobarzanis, quod finitimum est uestris uectigalibus, totum esse in hostium potestate; Lucullum magnis rebus gestis ab eo bello discedere; huic qui succurrit, non satis esse apparatum ad tantum bellum administrandum; unum ab omnibus sociis et ciuibus ad id bellum imperatorem deposci atque expeti; eundem hunc unum ab hostibus metui, praeterea neminem. Causa quae sit uidetis, nunc quid agendum sit considerate". Sic proposuit Cicero. (IR 128-129).

2.5) Muy largos ${ }^{22}$. Textos que ocupan más de una página, como la descripción de Siracusa (IR 76-77 [Cic.Verr.2.4.117-119]).

\section{3) Tema}

3.1) Político-moral: Son los más numerosos. Ponen de relieve la búsqueda del bien común, el sacrificio del gobernante en aras de la salvación del Estado, el sentido del deber, la denuncia de la tiranía, la censura de la corrupción...; también los hay destinados a exaltar virtudes como la honradez, justicia, lealtad, generosidad, prudencia, y denunciar los vicios que se oponen a estas: injusticia, traición, codicia, temeridad, abuso de poder...:

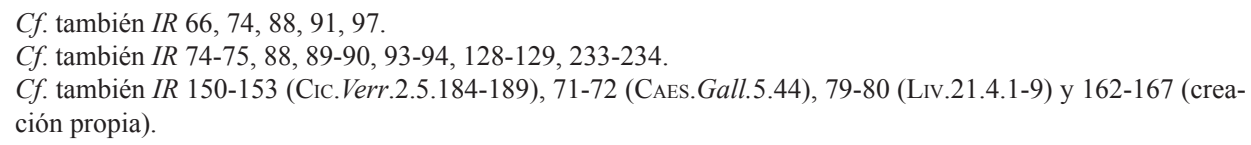


Praestantissimus uero omnium auersione utendi modus is est, si quos obiurgare coram de re quapiam non audemus, eos per auersionem in rem uel personam absentem reprehendamus. Veluti si regem aut uirum opibus potentem, aut eum cui reuerentiam et honorem debeamus, aut eum ex cuius offensione aliquid nobis periculi timeamus. Id ego uno exemplo aperiam. Regem tyrannidis coram reprehendere non audes? Conuerte orationem ad aliquem ex his qui rempublicam oppresserunt eumque urge acriter, reprehende, accusa, damna. Idem poteris efficere per auersionem in tyrannidem. Poteris et hoc ipsum auersione in res alias ostendere, sed mihi ad illustrandam rem satis est unius exempli (IR 179-180).

3.2) Diferentes ramas del saber ${ }^{23}$ : derecho, historia, filosofía, gramática...:

Res haec [uitiosa causa] uno illustrabitur exemplo quod quoniam de iure Romano antea exemplum attulimus de eodem nunc erit. Prima pars quae est de iure personarum primo loco tractetur: sint hominum alii liberi alii serui et omnes suis definitionibus explicentur. Deinde ponatur rerum diuisio quarum summa haec est ut quaedam in patrimonio nostro, quaedam extra patrimonium habeantur atque his subiices definitiones quibus percipiantur [...] (IR 233-234).

3.3) Personajes mitológicos o históricos, paisajes, naturaleza ${ }^{24} \ldots$. Apud Iulium Caesarem etiam sunt percrebrae personarum descriptiones, ueluti regulorum Galliae et Heluetiorum, ut Orgetorigis, Castici, Dummoterigis, Verodactii, Ariouisti, Voluseni, Comii Atrebatum regis et aliorum innumerabilium (IR 80).

3.4) Otros ${ }^{25}$. Se trata de ejemplos misceláneos, de contenido heterogéneo: Alterum atque postremum genus figurarum ingenii superlatio nominatur, id est, augendi minuendiue causa ueritatis traiectio. Talia sunt illa: "Rupes in coelum", "tendit ad sidera clamor", "lepore timidior", "magis ater quam coruus", "durior adamante” (IR 95).

Cada uno de los tres libros de las $I R$ posee sus propias características en cuanto a la tipología y extensión de intertextos ejemplificativos, pues estos están organizados en función de la parte de la preceptiva a ejemplificar. Por ejemplo, el L. I, dedicado a la elocutio, es el que más abunda en ejemplos breves, pues estos ilustran las figuras simples, siendo en su mayoría citas textuales. El L. II, dado que trata la dispositio, es el que contiene más paráfrasis y referencias, ya que para ilustrar partes del discurso como el exordium, la narratio o ejemplificar la amplificatio o la digressio sería demasiado prolijo desarrollar extensas citas textuales. El L. III, dedicado a la exercitatio, que retoma procedimientos de la elocutio como la derivación, los arcaísmos y sus defectos de uso, destaca por el empleo de citas muy breves.

Por lo que se refiere al contenido, en el L. I destaca el bloque temático políticomoral con diferencia sobre los demás $(72,3 \%)$, seguidos del de ejemplos referidos a la elocuencia (4,60\%); el resto son casi todos de carácter misceláneo ( $c f$. gráfico 1). En el L. II también predomina el mismo bloque de contenido político-moral con un $85 \%$, seguido de ejemplos referentes a historia con un $7 \%$ ( $c f$. gráfico 2). En cambio, el L. III se desvía un poco de esta tendencia, con un alto predominio de ejemplos de

\footnotetext{
Cf. también IR 81, 259, 260, 267.

Cf. también IR 72-73, 75, 271.

Cf. también IR 21, 29, 136, 173, 270.
} 
contenido heterogéneo $(83,68 \%)$, seguido a mucha distancia por un $6,41 \%$ de ejemplos político-morales y un 4,96\% de carácter gramatical ( $c f$. gráfico 3).

En cuanto a la autoría de los ejemplos, en el L. I la mayoría son de Cicerón $(40,8 \%)$, seguido de ejemplos propios de Furio $(21 \%)^{26}$; en tercer lugar, Virgilio (7,9\%) y Quintiliano (5,3\%), y por detrás Terencio (4\%), César, Marcial y Ovidio (cada uno con un 3,1\%). Entre todos suman el 88,3\% de los ejemplos. Los ejemplos restantes corresponden a un grupo misceláneo de autores, tanto de la Antigüedad como contemporáneos, utilizados una o dos veces a lo sumo, por ejemplo, Apuleyo, Catulo, Horacio, Juvenal, Livio, Salustio, Tibulo, Rutilio Lupo, Poliziano o Calvete de Estrella ( $c f$. gráfico 4).

En el L. II se repite más o menos el modelo anterior. Sigue predominando Cicerón con el $53 \%$ de ejemplos; a continuación, pero a distancia, el propio Furio (17,5\%), Virgilio y Ovidio con un 5,26\% cada uno, y Terencio, César y Silio Itálico con un $2 \%$ cada uno ( $c f$. gráfico 5 ).

Sin embargo, en el L. III se aprecia una inversión en las preferencias de Furio, siendo interesante el hecho de que, en un libro dedicado a la exercitatio, en el que el valenciano aconseja no imitar únicamente a Cicerón (IR 219), la mayoría de ejemplos son del propio Furio (66,47\%, frente al $25,88 \%$ de Cicerón). El resto de autoridades citadas es muy pequeño, no llega al $8 \%$ ( $c f$. gráfico 6 ).

Centrándonos en los ejemplos de Cicerón, en los libros I y II predominan los pertenecientes a la obra oratoria (77,41\% y $85,52 \%$, respectivamente), en especial In Catilinam, Pro Murena, In Verrem, Pro lege Manilia, Pro Cluentio, Pro Flacco y Pro Caelio. En cambio, en el L. III la mayoría procede de obra filosófica (Timaeus, De officiis, De natura deorum...) con un 47,74\%, y retórica (De oratore, Academica, De inuentione, Orator...) con un 36,36\%; los pertenecientes a oratoria (In Verrem, Pro Cluentio, Philippicae) solo representan el 15,9\% (cf. gráficos 7 y 8).

Resumiendo lo visto hasta ahora, el análisis estadístico de los ejemplos en el conjunto de los tres libros de $I R$ permite concluir que en las categorías de tipología y extensión Furio prefiere citas directas y ejemplos breves ( $c f$. gráficos 9 y 10). Por lo que respecta a las fuentes, tiene como autoridades principales primero a Cicerón ${ }^{27} \mathrm{y}$ luego a sí mismo ( $c f$. gráfico 11). En cuanto a la temática, la que predomina es la de carácter político-moral ( $c f$. gráfico 12).

Esta preferencia por los ejemplos de contenido político, que en el L. I alcanza el $72,3 \%$ y en el L. II se eleva al $85 \%$, hace pensar en una clara intencionalidad en la selección del material de ejemplificación con el fin de explotar su potencial connotativo, en cuyo caso los ejemplos cumplirían una doble función ilustrando, por una parte, la teoría retórica, y dejando traslucir, por otra, las líneas maestras del pensamiento político de Furio. Dado que el valenciano desarrolla ampliamente este ideario cinco años después en $E C$ a través de las cualidades del Consejero, hemos contrastado los ejemplos de temática político-moral con dichas cualidades para comprobar si la hipótesis que hemos planteado puede verificarse.

26 No podemos descartar la posibilidad de que, tanto en este libro como en los dos restantes, se nos haya pasado por alto la localización de la auténtica fuente de algún ejemplo, pues existen ciertos casos en los que Furio no la explicita (hemos detectado 10 ejemplos de Quintiliano, 5 de A. Romano, y al menos 12 que aparecen en $D e$ copia uerborum y en los Adagia de Erasmo).

27 Los discursos más utilizados son Verrinas y Catilinarias, en los que se denuncia la corrupción, la traición, el abuso de poder y la tiranía, y En defensa de Murena, personaje del que Cicerón destaca sus dotes como general $\mathrm{y}$ orador, y al que atribuye las cualidades de justicia, lealtad, honradez y prudencia. 


\section{Las cualidades del Consejero reflejadas en los ejemplos de Institutionum Rhetoricarum libri tres}

De las quince cualidades del alma que en $E C$ se atribuyen al buen consejero y demuestran su suficiencia, presentamos aquí la segunda, la sexta, la octava, la novena, la undécima y la decimotercera; junto a cada una de ellas hemos añadido un ejemplo de $I R$ que en nuestra opinión guarda correspondencia con ellas por su significado connotativo.

Paralelamente, hemos querido acercarnos al corpus de ejemplos de los Institutionum Dialecticarum libri tres, las Institutiones Oratoriae y la Rhetorica de Ramus y Talon, referentes principales de la preceptiva de Furio, con el fin de comprobar si este material es utilizado a modo de 'banco de ejemplos' para ilustrar la parte teórica correspondiente (o equivalente) de $I R$ y, de ser así, si sufre alguna reelaboración o modificación.

\section{Segunda cualidad: Elocuencia}

La justificación de la importancia de la elocuencia ${ }^{28}$ dada por Furio en $E C$ se identifica claramente con este ejemplo de $I R$ empleado para explicar la figura de la complexio:

\section{$E C$}

La segunda calidad, que muestra la suficiencia del alma en el Consejero, es que sepa las artes del bien hablar; porque como los hombres nos diferenciamos de todas las alimañas con el entendimiento i palabra, de creer es que entre los hombres, aquellos son más ecelentes que saben mejor i con más gracia hablar i razonar. [...] Mas, que en una rebuelta i motín de un campo, en unas comunidades, i otros movimientos desarreglados, quanto uno fuere más exercitado en bien hablar, tanto terná mejor oportunidad de lo apaziguar. Assí mesmo aprovecha para dar buenas, graves, i sotiles respuestas de palabra i por escrito a los embaxadores que vinieren a negociar con el Príncipe (EC 101).
$I R$

Complexio repetitio est quae ex anaphora et conuersione constat, nam principiis aliquid iteratur et extremis aliquid. Vt, "Quis potuit homines uagos et siluestres in ciuitates includere? Eloquentia. Quis ciuitatibus constitutis leges imposuit? Eloquentia. Quis ciuitatum communionem retinet atque conseruat? Eloquentia" (IR 50).

En $I R$ Furio destaca con este ejemplo de creación propia, inspirado en Cicerón (de orat.1.33), la misión civilizadora y apaciguadora de la elocuencia - ¿¿Quién ha podido contener en ciudades a hombres errantes y salvajes?... ¿Quién ha impuesto leyes a las ciudades tras su fundación?... ¿Quién mantiene y conserva la unión en las ciudades...?»)-, porque es el orador quien, por medio de la palabra y a través de ella, construye, vertebra y conserva la sociedad. La idea, como puede apreciarse, es la misma que leemos en $E C$ acerca de la elocuencia. 
Talon $(1545,61$ y 1552, 62) emplea para ilustrar esta figura (que él denomina symploce, siue complicatio) dos citas de Cicerón (Agr.2.2 y Mil.59). Furio aprovecha el ejemplo de Agr.2.2, pero colocándolo tras su propio ejemplo sobre la elocuencia.

\section{Sexta cualidad: Conocimiento de estrategia político-militar interior y exterior}

No siempre es fácil, como en este caso, interpretar el sentido moderno de las palabras de Furio, que define esta cualidad como ser «plático en el govierno de paz i de guerra, i cosas a ello pertenescientes». Esta cualidad ha sido interpretada como «sentido práctico de gobierno en paz y en guerra» (Merchán 2002, 560) o «conocimiento de los diferentes mecanismos de gobierno» (Villacañas 2015, 67). En nuestra opinión, Furio se está refiriendo con ella a las competencias del Consejero como estratega $^{29}$ (idea inspirada en el capítulo 14 de El Príncipe de Maquiavelo [19832, 106-109], donde el florentino expone lo que corresponde hacer al Príncipe en el arte de la guerra). Dichas competencias se reflejan con exactitud en el siguiente ejemplo de $I R$, que es una cita textual extraída de Quintiliano (inst.2.13.3-4), empleada por Furio para introducir el capítulo dedicado a la dispositio prudentiae:

$E C$

La sexta calidad que muestra la suficiencia del alma en el Consejero, es que sea político, digo, que sea plático en el govierno de paz i de guerra, i cosas a ello pertenescientes $[\ldots]$ ¿Qué es mejor, aguardar al enemigo en nuestras tierras o irlo a buscar a las suias? ¿Quántas cosas debe considerar un Príncipe antes de romper guerra, quántas cosas después de rota, quántas cosas antes de dar la batalla, quántas después de ser vencedor o vencido? Con la respuesta que diere a estas i semejantes preguntas, se podrá coligir quán buen Repúblico sea el Consejero (EC 105107).

Furio destaca de este ejemplo de $I R$ la capacidad del buen general para elegir «la mejor y más sólida organización» del ejército, seleccionar «la naturaleza del lugar» adecuado para entablar combate, estudiar «la clase de enemigos, si son fuertes y valientes, o débiles, pocos o muchos...», valorar «la condición del peligro real» y actuar en consecuencia, etc., actitud que se corresponde con la del consejero «plático en el govierno de paz i de guerra».

En la Dialectica de Ramus $(1550,277)$ este ejemplo es empleado en las notas atribuidas a $\mathrm{O}$. Talon sobre la methodus prudentiae. Furio usa el mismo ejemplo en un contexto teórico equivalente (la dispositio prudentiae), pero no respeta la litera-
Et quemadmodum eleganter dixit Fabius, bonus Imperator non solum in acie instruenda diriget frontem, cornua utrinque promouebit, equites pro cornibus locabit (quae est certissima et tutissima construendi ratio) uerum etiam aliter atque aliter exornabit, uertet, inuertet pro natura loci, siue superioris siue inferioris: si mons ocurret, si palus, si flumen obstabit, si collibus et syluis prohibebitur; pro hostium genere, si fortes et strenui, si imbelles, si pauci, si multi fuerint; pro tempore ut si hibernum, si aestuans nimis fuerit. Denique pro praesentis periculi conditione, nunc acie directa, nunc cuneis, nunc phalange, nunc uelitibus, nunc catafractis, nunc peditatu, nunc equitatu pugnandum est: non raro etiam simulasse fugam prodest (IR199). 
lidad de la cita, ya que varía las construcciones, el orden y las palabras de la misma para adaptarla a sus propósitos. En este sentido, destaca la sustitución del comienzo original de Quintiliano Quid si enim praecipias imperatori... derigat por el bonus Imperator... deriget de Furio.

\section{Octava cualidad: Sentido de Estado}

Con esta competencia Furio se refiere al dominio en el manejo de los asuntos interiores del propio Estado y de las relaciones con los Estados vecinos ${ }^{30}$. Está muy bien ilustrada con el siguiente ejemplo de $I R$ tomado de Cicerón (Manil.4-5) que Furio emplea al hilo de la propositio:

\section{$E C$}

La otava cualidad que muestra la suficiencia del alma en el Consejero, es que sepa las fuerças i Poder de su Príncipe, de sus aliados, de sus enemigos i vecinos. Porque, como un médico la primera cosa que mira en un cuerpo humano es su temperamento y su virtud natural para quanto es, de la mesma manera el Consejero debe saber quántas son, quáles, i a quánto bastan las fuerzas (sic) i poder de su Príncipe, de sus enemigos i de sus aliados; porque, de otra manera, nunca dará consejo que vala. Por no saber esto, los Consejeros mueven su Príncipe a hazer guerras a vezes con quien devrían bivir en paz, i amonestan de hazer pazes con quien sería menester hazer guerra [...] El buen Consejero trabaja de saber en ambas partes de su Príncipe i adversario i aliados, quántas sean las rentas ordinarias i estraordinarias, de do las sacan, cómo i en qué tiempo; qué tanta gente de guerra puedan levantar i sostener, i por quánto tiempo (EC 109).

\section{$I R$}

Proponendi altera forma ex pluribus constat uerbis; huiuscemodi est illa Ciceronis Pro lege Manilia: "Atque ut inde oratio mea proficiscatur unde haec omnis causa ducitur, bellum graue et periculosum uestris uectigalibus atque sociis a duobus potentissimis regibus infertur, Mithridate et Tigrane, quorum alter relictus, alter lacessitus, occasionem sibi ad occupandam Asiam oblatam esse arbitratur. Equitibus Romanis honestissimis uiris afferuntur ex Asia quotidie literae, quorum magnae res aguntur in uestris uectigalibus exercendis occupatae; qui ad me, pro necessitudine quae mihi est cum illo ordine, causam reipublicae, periculumque rerum suarum detulerunt, Bithyniae, quae nunc uestra prouincia est, uiros exustos esse complures; regnum Ariobarzanis, quod finitimum est uestris uectigalibus, totum esse in hostium potestate; Lucullum magnis rebus gestis ab eo bello discedere; huic qui succurrit, non satis esse apparatum ad tantum bellum administrandum; unum ab omnibus sociis et ciuibus ad id bellum imperatorem deposci atque expeti; eundem hunc unum ab hostibus metui, praeterea neminem. Causa quae sit uidetis, nunc quid agendum sit considerate". Sic proposuit Cicero (IR 128-129).

En este ejemplo Cicerón, pretor en ese momento, demuestra conocer a la perfección la realidad de la guerra contra Mitrídates y las repercusiones económicas, sociales y políticas que el conflicto puede ocasionar en los intereses y el bienestar de la república $-« \ldots$ una guerra pesada y peligrosa se declara contra vuestros tributarios y aliados... que tienen en juego importantísimos capitales en la administración de vuestros tributos... me encomendaron la defensa de la república y de sus intereses en peligro... Veis, pues, cuál es el planteamiento, ahora pensad qué debe hacerse»-, y decide informar al senado movido por su sentido de Estado. De nuevo, son signifi- 
cativas las similitudes entre la actitud de Cicerón para con el senado y la disposición que, según Furio, debe mostrar un buen consejero con su Príncipe.

Ramus $(1550,263)$ emplea a Ovidio para ilustrar la propositio (fast.1.1-2) y la partitio (fast.1.27-28 y 43-44), a la que añade un ejemplo breve del discurso Pro lege Manilia (Cic.Manil.6). Furio emplea los mismos ejemplos para la partitio, pero para ilustrar la propositio se desvía de Ramus, cambiando el ejemplo breve de Ovidio por uno largo del mismo Pro lege Manilia de Cicerón, pero de un momento anterior (Manil.4-5), para centrar el foco de interés en el desarrollo del ejemplo y explotar todas las posibilidades connotativas del fragmento.

\section{Novena cualidad: Espíritu de sacrificio}

Esta cualidad, consistente en la renuncia del individuo al propio beneficio en pro del bien público (similar a la idea expresada por Maquiavelo en el capítulo 22 de El Príncipe [19832, 106-109] cuando describe al secretario del Príncipe), es una de las que mejor puede rastrearse en $I R^{31}$. Furio lo hace fundamentalmente con ejemplos tomados de Cicerón, como este (Catil.4.1-2) que emplea a propósito de los exordios a persona:

\section{$E C$}

La novena cualidad que muestra la suficiencia del alma en el Consejero, es que no solamente ame el bien público, pero que en procurarlo se olvide de su propio provecho i reputación; de tal manera que, do se pueda aprovechar al bien común, el Consejero se debe emplear en ello con todas sus fuerças i diligencia, aunque de allí se le haia de recrescer daño propio en fama, vida i bienes. [...] Cierto es i averiguado que el amor verdadero es vigilante i solícito; la solicitud jamás reposa, todo lo mira, todo lo vee; en nada se descuida, $i$ así provehe en todo lo necessario; i por tanto es el amor, qual digo, una de las buenas calidades del Consejero. Este mesmo amor, siendo verdadero, de necesidad es que estime i procure mucho más el bien público que el suio (EC 110).
$I R$

A persona item sua fecit orandi initium Cicero In Catilinam cum summa testificatione rerum suarum: "Video, patres conscripti", inquit, "in me omnium uestrum ora, atque oculos esse conuersos, uideo uos non solum de uestro ac reipublicae, uerum etiam, si id depulsum sit, de meo periculo esse sollicitos. Est mihi iucunda in malis et grata in dolore uestra erga me uoluntas. Sed eam per deos immortales quaeso deponite, atque obliti salutis meae, de uobis ac liberis uestris cogitate. Mihi quidem sic haec condicio consulatus data est, ut omnes acerbitates, omnes dolores cruciatusque perferrem, feram non solum fortiter, sed etiam libenter, dummodo meis laboribus uobis populoque Romano dignitas salusque pariatur. Ego sum ille consul, patres conscripti, cui non forum, in quo omnis aequitas continetur, non campus consularibus auspiciis consecratus, non curia, summum auxilium omnium gentium, non domus, commune perfugium, non lectus ad quietem datus, non denique haec sedes honoris sella curulis unquam uacua mortis periculo atque insidiis fuit. Ego multa tacui, multa pertuli, multa concessi, multa meo quodam dolore in uestro timore sanaui" (IR 115-116).

En este ejemplo se evidencia el paralelismo entre la voluntad de entrega y compromiso exigibles al consejero «de tal manera que, do se pueda aprovechar al bien

$31 C f$. también sobre esta misma temática $I R$ 44, 45, 97, 153, 174, 191. 
común, el Consejero se debe emplear en ello con todas sus fuerças i diligencia, aunque de allí se le haia de recrescer daño propio en fama, vida i bienes», y la desplegada por Cicerón cuando el cónsul declara que, a pesar de su exposición a infinidad de peligros, está dispuesto a «soportar todas las amarguras, todos los dolores y angustias... no solo con fortaleza, sino incluso de buena gana con tal que mis fatigas aseguren vuestra dignidad y la salvación del pueblo romano».

\section{Undécima cualidad: Justicia}

Está competencia está muy relacionada con la décima cualidad (imparcialidad), que se considera virtud inexcusable en la aplicación de la justicia. De la justicia destaca Furio su valor intrínseco y universal, y la necesidad de ejercerla en aras de reconocer y recompensar los méritos propios de cada individuo ${ }^{32}$ (en clara afinidad con lo dicho por Maquiavelo en Discursos sobre la primera década de Tito Livio, 1.24 [1987, 95-97], donde el florentino expone cómo los estados bien organizados instituyen premios y castigos para sus ciudadanos). Todo ello se refleja bien en un ejemplo de $I R$ sobre la interrupta prosopopoeia (dialogismo), que es una cita textual larga de Cicerón (Manil.61-62):

\section{$E C$}

La onzena calidad que muestra la suficiencia del alma del Consejero es que sea justo i bueno; porque el tal es amigo de pagar a cada uno según sus méritos, que es castigar al malo i remunerar al bueno. [...] No puede ser justo el que no pone todas sus fuerças noche i día continuamente en que gane honra i hazienda por medio de virtud. No puede ser justo el que, meresciendo en virtud i por virtud, se descuida de pedir premio i testimonio de su merescimiento, porque el tal haze agravio a sí i a los suios, escuresce la virtud, i daña a la República (EC 113-114).

\section{$I R$}

"Quid tam nouum quam adolescentulum priuatum exercitum difficili reipublicae tempore conficere? Confecit. Huic praesse? Praefuit. Rem optime ductu suo gerere? Gessit. Quid tam praeter consuetudinem quam homini peradolescenti, cuius a Senatorio gradu aetas longe abesset, imperium atque exercitum dari, Siciliam permitti atque Aphricam bellumque in ea administrandum? Fuit / [92] in his prouinciis singulari innocentia, grauitate, uirtute, bellum in Africa maximum confecit, uictorem exercitum deportauit. Quid uero tam inauditum quam equitem Romanum triumphare? Et eam quoque rem populus Romanus non modo uidit, sed etiam studio omni uisendam putauit. Quid autem tam inusitatum quam ut, cum duo consules clarissimi fortissimique essent, eques Romanus ad bellum maximum formidolosissimumque pro consule mitteretur? Missus est" (IR 91-92).

Este mismo ejemplo es utilizado por Talon $(1552,34)$ para ilustrar la prolepsis, pero con una extensión mucho más breve, pues solo emplea las tres primeras interrogaciones. Furio, en cambio, alarga el ejemplo considerablemente, añadiendo el momento en que Cicerón loa las extraordinarias cualidades de Pompeyo -innocentia, grauitas, uirtus - que este puso al servicio de la república y le hicieron merecedor de

32 Cf. también IR 43, 98, 143, 147, 155-157, 201. 
un triumphum -perteneciendo al orden ecuestre-, y de ostentar poderes proconsulares, cosa que el pueblo romano pensó «que debía verse y celebrarse con entusiasmo unánime». El subtexto es claro: el acceso a los puestos de responsabilidad en la gobernanza del estado no depende del nacimiento, sino de las propias cualidades, en una clara defensa de la meritocracia expuesta en esta competencia de $E C$.

\section{Decimotercera cualidad: Espíritu de servicio}

Esta cualidad, que consiste en un compendio de virtudes que convergen en la voluntad de hacer el bien al prójimo tanto a título individual como general (descrita por Maquiavelo en Discursos sobre la primera década de Tito Livio 1.2 [1987, 34] en el contexto de las diferentes formas de gobierno que se sucedieron en la antigua Roma), se refleja en los ejemplos de $I R$ a través de la expresión de dichas virtudes y de los vicios que se oponen a estas ${ }^{33}$. Esta síntesis de virtudes queda patente en un ejemplo de creación propia usado por Furio para explicar la communio (zeugma):

\section{$E C$}

La trezena calidad que muestra la suficiencia del alma en el Consejero, es que sea benéfico, digo, amigo de hazer bien. Esta virtud es la que en latín se llama beneficentia, i no se refiere a dar dinero, o algo de la hazienda, como lo da la liberalidad, sino en aiudar a la República (digo al bien común) i a todos sus miembros particulares aconsejando, amonestando, loando, vituperando, reprehendiendo, consolando, esforçando, procurando, i favoresciendo con su autoridad i amparo, no sólo a aquellos que le piden favor $\mathrm{i}$ aiuda, sino también a todos aquellos que lo merezcen sin que lo pidan. Lo que viene a llamarse un defensor del pueblo, padre de la patria, y casi Dios en la tierra (EC 113).

\section{$I R$}

Communio est defectionis genus, quod in pluribus eiusmodi membris consistit, inter quae aliquid est commune, quod tamen in uno positum in reliquis desideratur. Quod tametsi in omnibus orationis partibus reperiatur, nos tamen uno aut altero exemplo ad rem explicandam contenti erimus. In nomine sic fit communio: "Bonus ciuis bene de republica sentit et loquitur, statum reipublicae tuetur, mala impendentia illi longe propellit, cauet ne quid ei detrimenti inferatur, ciues suos fratrum loco habet, denique nec, si res ferat, dubitet pro reipublicae salute crudelissimum mortis genus pati" (IR 44).

Furio consigue con este ejemplo de creación propia casi una transliteración de la cualidad que «en latín se llama beneficentia», y consiste en «aiudar a la República (digo al bien común) i a todos sus miembros particulares»:

El buen ciudadano siente y habla bien de la república, defiende el estado de la república, aleja las amenazas que se ciernen sobre ella, procura que no se le inflija ningún daño, considera a sus conciudadanos como sus hermanos $\mathrm{y}$, finalmente, si las circunstancias lo exigen, no duda en sufrir la más cruel de las muertes por la salvación de la república.

Talon $(1545,65)$ ilustra esta figura con una cita textual de Cicerón usada por Quintiliano (inst.9.3.62). Furio usa también este ejemplo, pero lo enmarca entre

33 Cf. también IR 47, 49, 55, 56, 88, 89-90, 93, 95, 99-100, 101, 111, 114-115, 145, 146, 147, 191. 
otros dos, ambos de creación propia, el primero -reproducido más arriba- resaltando las características del buen ciudadano, y el segundo incidiendo en la prudencia y valor personal frente a las amenazas de diversa índole: "Nec timuit obscurae noctis pericula, nec hostis insidias, nec tela, nec ignes, omnia uicit, non audacia nec temeritate, sed prudentia, consilio et animo grandi infractoque" (IR 44-45).

\section{Conclusiones}

La temática principal de los ejemplos utilizados en $I R$, de carácter político-moral, constituye un mundo de ideas, de principios y de valores entre los que destacan la búsqueda del bien común, el sacrificio del gobernante por la salvación del Estado, el sentido del deber, y la denuncia de la corrupción y de la tiranía. En él se exaltan la honradez, la justicia, la lealtad, la generosidad, la prudencia, la valentía, y se censuran sus contrarios: la codicia, la temeridad, la injusticia, la traición... Este discurso se corresponde con los ideales de paz, concordia, entrega al Estado y sacrificio en defensa del interés general, y con las virtudes de los servidores públicos defendidos en $E C$. Del mismo modo, la ausencia de ejemplos bíblicos o patrísticos refuerzan la vocación laica del proyecto político de Furio; en palabras de Méchoulan-Almenara (1996, 60), «adelantándose a su tiempo, ha separado al político del teólogo».

Paralelamente, los intertextos ejemplificativos analizados demuestran que Furio aprovecha y reutiliza ejemplos de las obras de Ramus y Talon, pero cuando lo considera oportuno los retoca, cambia su tipología, su extensión e incluso las fuentes, reemplazando los ejemplos de sus maestros parisinos por otros más acordes con su objetivo de divulgación ideológica.

A propósito de las fuentes de los ejemplos, siendo Cicerón y el propio Furio las autoridades más empleadas, se hace difícil no apreciar el paralelismo que sutilmente establece el valenciano entre el Arpinate y él mismo, por lo que respecta a la dimensión retórica, como maestros de elocuencia y, en lo referente a la dimensión social y política, como encarnaciones del ideal de servidor público digno de alcanzar la cima del cursus honorum por propio merecimiento.

Teniendo en cuenta todo ello, creemos poder afirmar que los ejemplos elegidos por Furio para sus Institutionum rhetoricarum libri tres no solo ratifican su condición de retórica civil concebida para la política, sino que, además, apuntan y perfilan ya el prototipo ideal de político altamente cualificado, consumado orador, profesional, experimentado y virtuoso, que Furio presentará como modelo de consejero en El Concejo, $i$ Consejeros del Príncipe. Elevados a una esfera eminente en el marco de un proyecto ideológico global y dentro una minuciosa planificación, los ejemplos de este manual se convierten no solo en un punto de apoyo para la teoría retórica de Furio, sino también, y he aquí su trascendencia, en portavoces de su teoría política. En palabras del propio Furio (IR 17), exempla, etiam me tacente, loquuntur. 


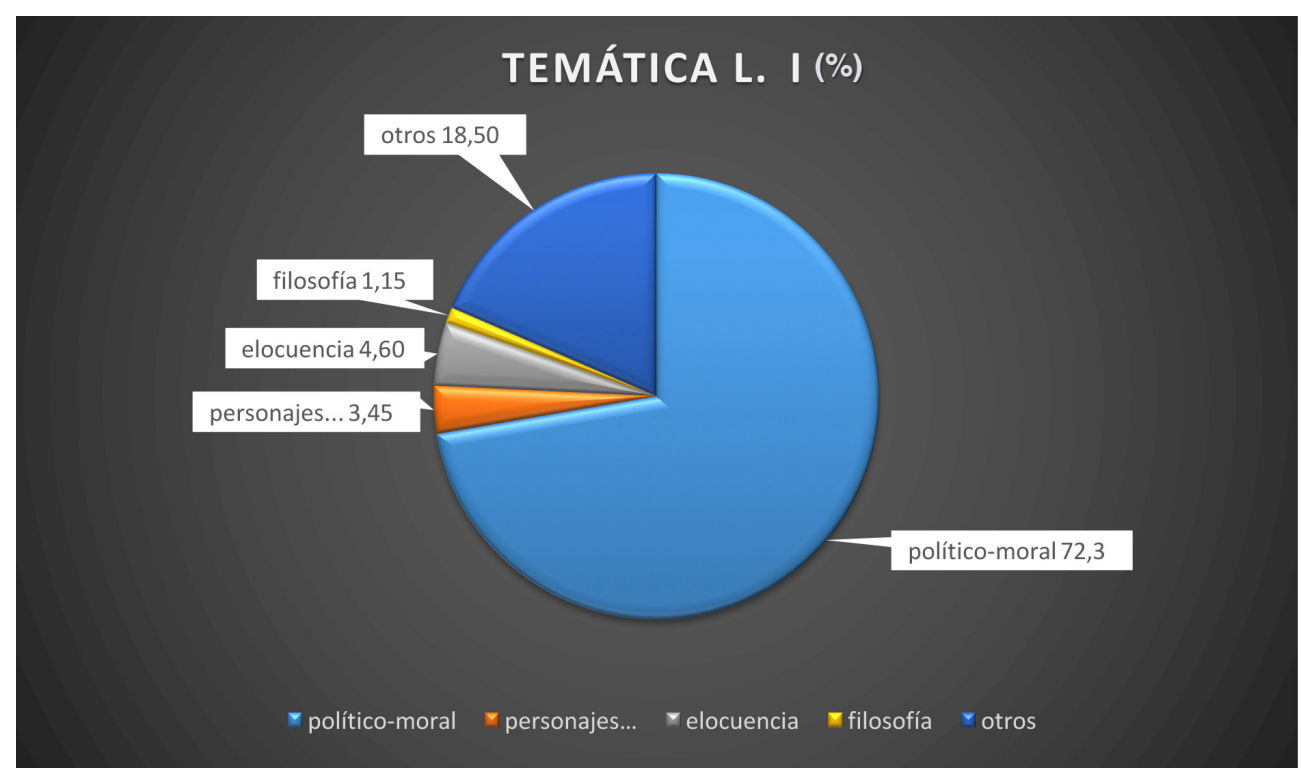

\section{Gráfico 1}

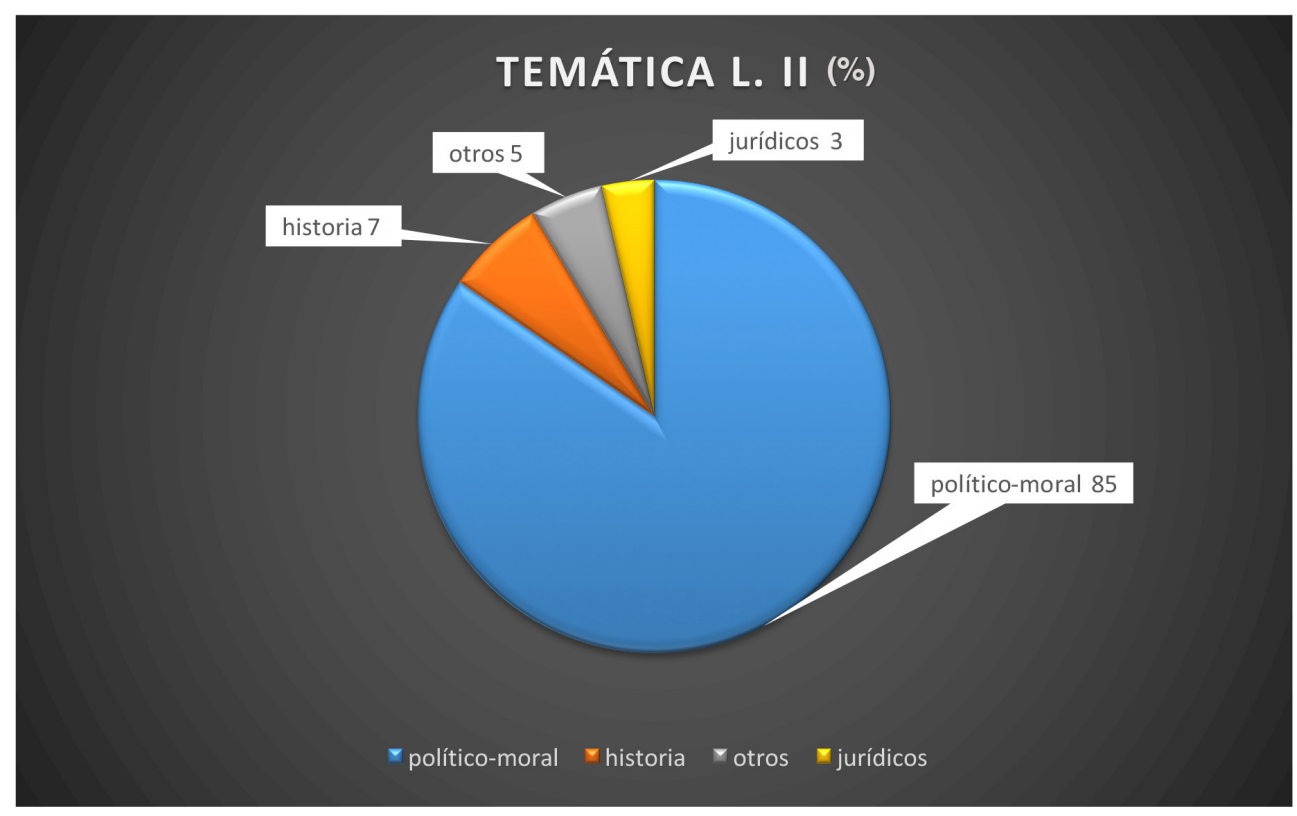

Gráfico 2 


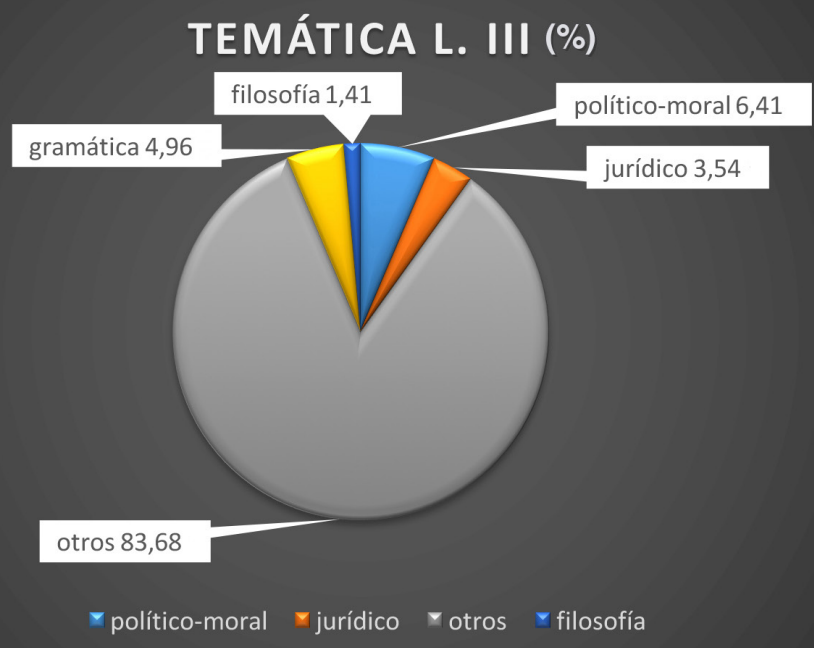

Gráfico 3

\section{FUENTES DE LOS EJEMPLOS - L. I (\%)}

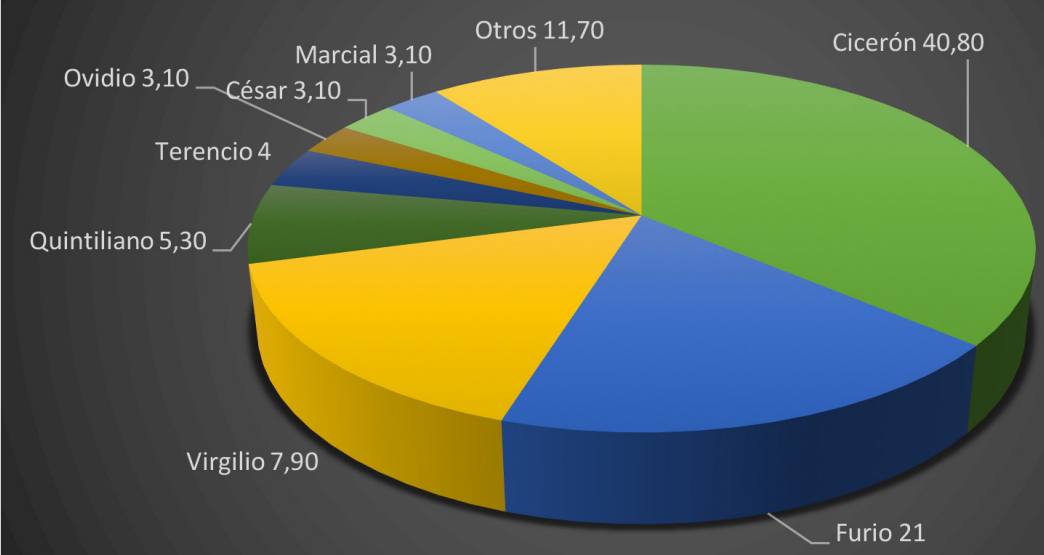

Gráfico 4 


\section{FUENTES DE LOS EJEMPLOS - L. II (\%)}

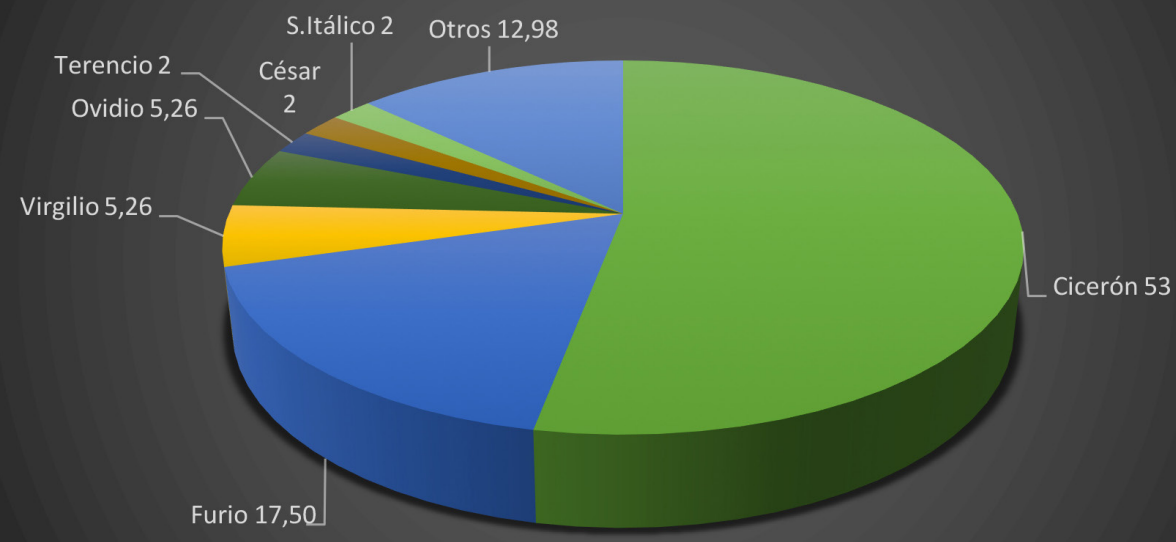

Gráfico 5

\section{FUENTES DE LOS EJEMPLOS - L. III (\%)}

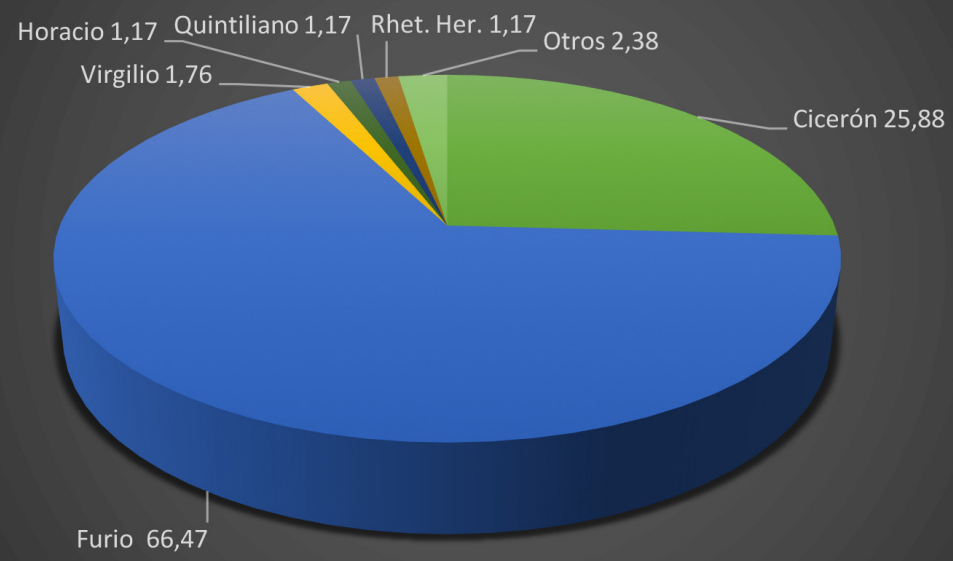

Gráfico 6 


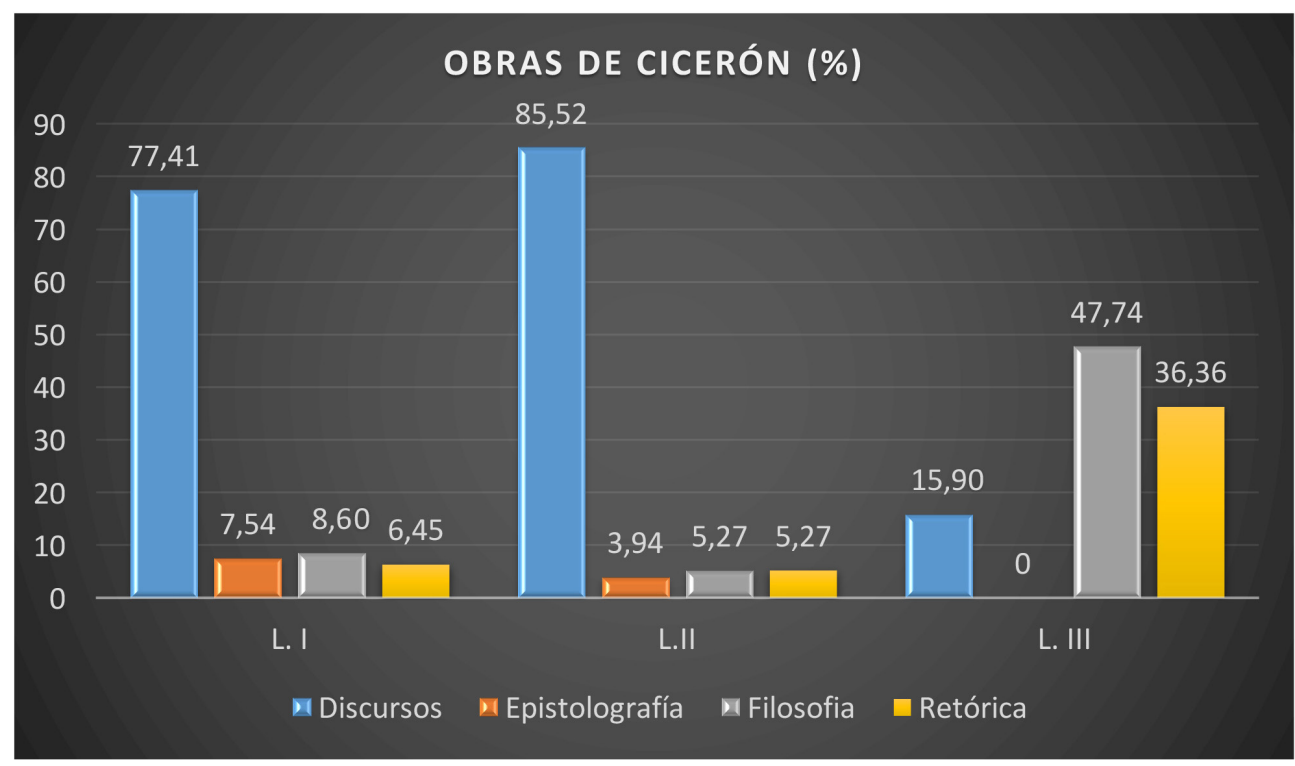

Gráfico 7

\section{DISCURSOS DE CICERÓN (\%)}

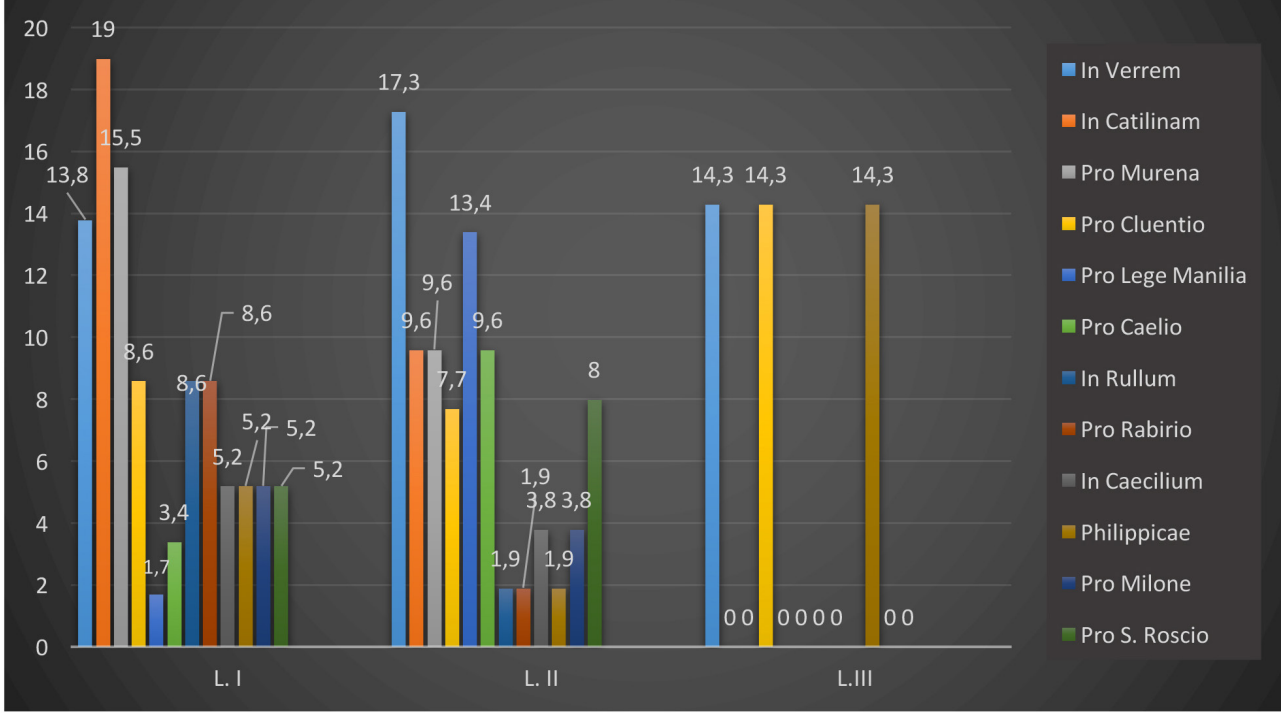

Gráfico 8 


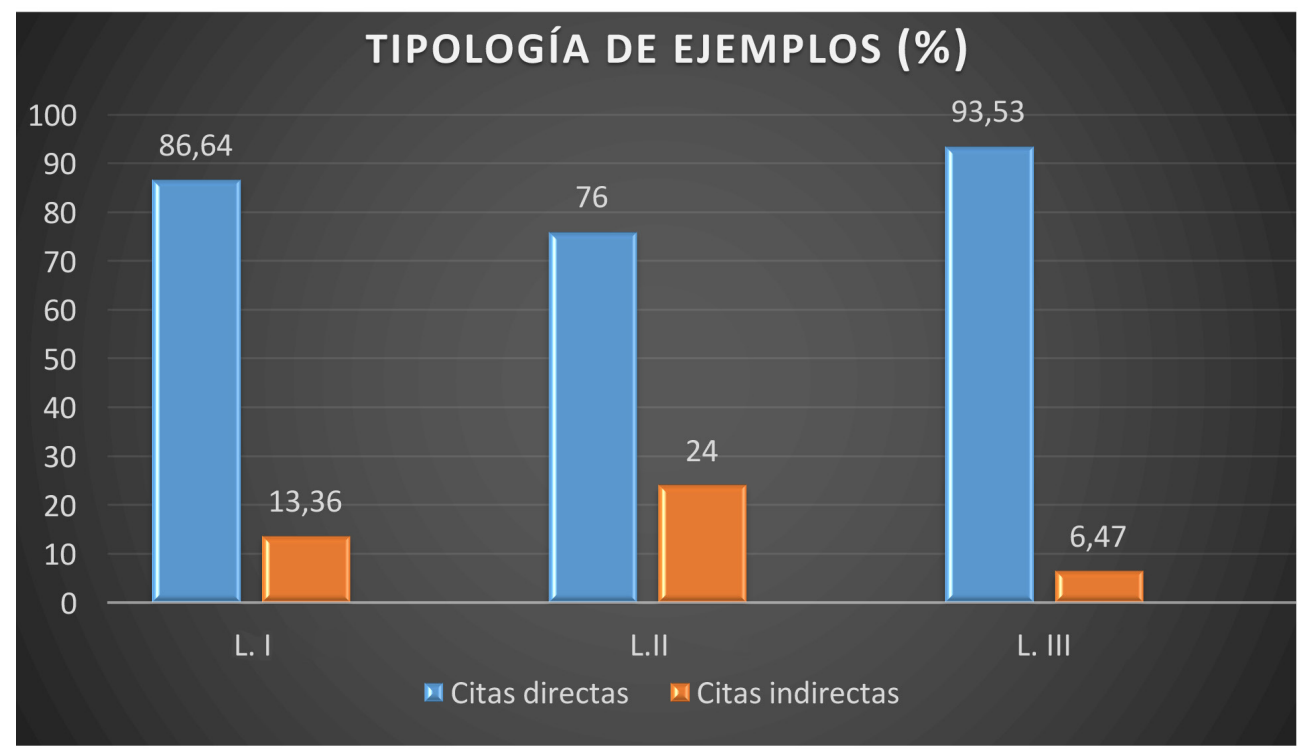

Gráfico 9

\section{EXTENSIÓN DE LOS EJEMPLOS (\%)}

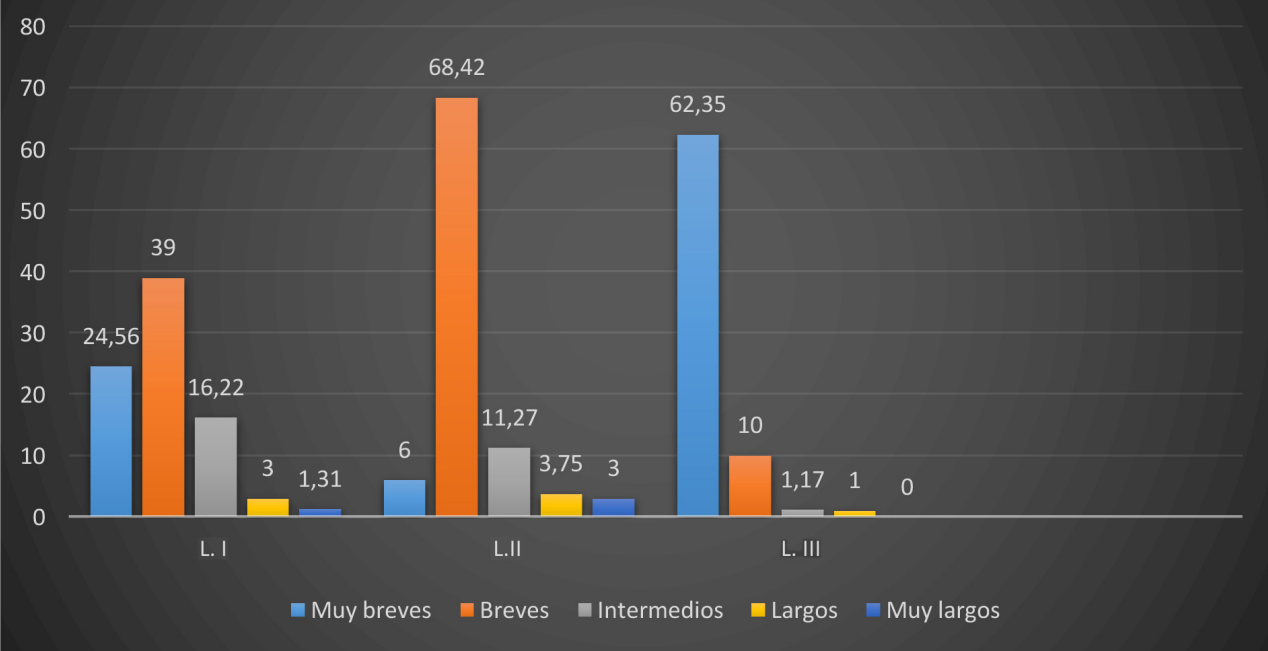

Gráfico 10 


\section{FUENTES DE LOS EJEMPLOS \\ L. I-III (\%)}

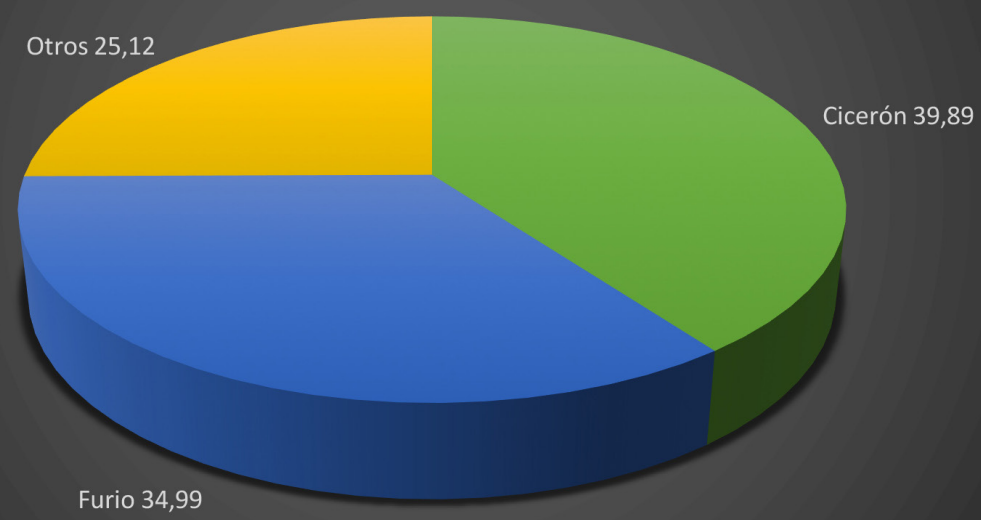

Gráfico 11

\section{TEMÁTICA DE LOS EJEMPLOS (\%)}

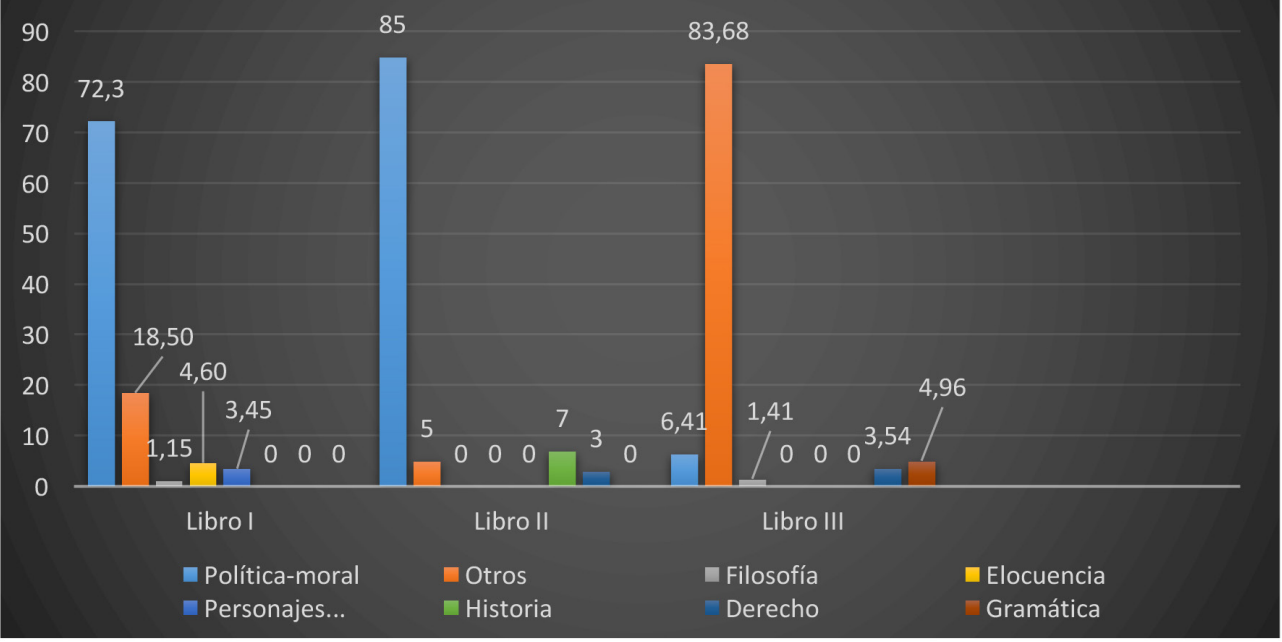

Gráfico 12 


\section{Bibliografía}

Almenara, M. - Ferragut, C. - Grau, F. (2021), «La Gramatica de la Lengua Vulgar de España (Lovaina, 1559), ¿anónima?», RFE 101 (enero-junio), 31-66. DOI: https://doi. org/10.3989/rfe.2021.002

Álvarez, H. (2016), «Fadrique Furió Ceriol: el precursor del estado laico en España», Revista de Derecho UNED 18, 659-682. DOI: https://doi.org/10.5944/rduned.18.2016.16900 [19-04-2021]

Aragüés, J. (1993), «Humanismo y literatura ejemplar (del pretendido rechazo al exemplum en la obra de Vives, Erasmo y Melchor Cano)», en Mourelle, M. (ed.), Juan Luis Vives (Valencia, 1492 - Brujas, 1540), Madrid, Grugalma, 121-147.

- (1997), «Ars dilatandi exempla. Teorías sobre la amplificación narrativa del exemplum en los siglos XVI y XVII», en Maestre, J. M. et al. (eds.), Humanismo y pervivencia del mundo clásico, II.2, Cádiz, Instituto de Estudios Turolenses - Universidad de Cádiz, 721-733.

D’Ascia, L. (1999), «Fadrique Furió Ceriol fra Erasmo e Machiavelli», Studi storici: rivista trimestrale dell'Istituto Gramsci 40.2, 551-584.

Ferragut, C. (2019), «La praxis de la retórica de Fadrique Furio Ceriol en El Concejo, i Consejeros del Príncipe: el ordo argumentorum», en Maestre, J. M. et al. (eds.), Humanismo y pervivencia del mundo clásico, VI.5, Alcañiz - Lisboa - México, Instituto de Estudios Humanísticos - Centro de Estudos Clássicos - Universidad Nacional Autónoma de México, s.p.

- (en prensa), «El Concejo y Consejeros del Príncipe de Fadrique Furio Ceriol o el autorretrato del consejero perfecto», en VIII Congreso de la SELAT. Otium Et Negotium. El Legado de Roma. Homenaje a la Dra. Francisca Moya del Baño, León, 29 de junio a 2 de julio de 2016.

Ferragut, C. - Grau, F. (2016), «La praxis de la retórica en la obra de Fadrique Furio Ceriol», en von der Walde Moheno, L. (ed.), Retórica aplicada a la literatura medieval y a los siglos XVI y XVII, México, Editorial Grupo Destiempos, 39-95. <http://roderic.uv.es/ handle/10550/56162>

Ferragut, C. - Teodoro, J. L. (2016), «Ex natura o ex praeceptis? La presencia de la natura en los Institutionum Rhetoricarum libri tres (1554) de Fadrique Furió Ceriol», en López, R. - Álvarez de Palacio, E. (eds.), Humanistas Españoles, Madrid, Ediciones Clásicas, 311-322.

Furio Ceriol, F. (1554), Friderici Furii Caeriolani Valentini, Institutionum Rhetoricarum libri tres, ad Georgium ab Austria Eburonum Pontificem, Lovanii: Ex officina Stephani Gualtheri et Ioannis Bathenii Typpog. Iurat.

- (1996), Obra completa I. El Concejo y Consejeros del Príncipe. Bononia, en Méchoulan, H. - Pérez Durà, J. (eds.), Valencia, Edicions Alfons el Magnànim.

García Pinilla, I. (2003), «La estructura de "Bononia" de Fadrique Furió Ceriol», en Grau, F. et al. (eds.), La Universitat de València i l'humanisme: Studia Humanitatis $i$ renovació cultural a la Europa i al Nou Món, Valencia, Universitat de València, 453-462.

Grau, F. (2000), «Los argumentos acerca de la retórica en Bononia de Fadrique Furió Ceriol», en Labiano, M. et al. (coords.), Retórica, política e ideología: desde la Antigüedad hasta nuestros dias, Salamanca, Logo, 383-388.

- (en prensa), «Methodus doctrinae y Methodus prudentiae en los Institutionum Rhetoricarum libri III de Fadrique Furio Ceriol», en VIII Congreso de la SELAT. Otium Et Negotium. El Legado de Roma. Homenaje a la Dra. Francisca Moya del Baño, León, 29 de junio a 2 de julio de 2016 . 
Harto, M. L. (2011), «El exemplum como figura retórica en el Renacimiento», Humanitas 63, 509-526.

Hermosa, A. (2010), «El concepto de política en Furió Ceriol», Quaderns d'Italià 15, 9-26. $<$ https://ddd.uab.cat/record/67709> [19-04-2021]

Lausberg, H. (1975), Elementos de retórica literaria. Introducción al estudio de la Filología Clásica, Románica, Inglesa y Alemana, Madrid, Gredos.

Lorenzo, J. (2003), «La retórica en la España del siglo XVI», en Codoñer, C. et al. (eds.), El Brocense y las Humanidades en el siglo XVI, Salamanca, Universidad, 191-210.

Luján, A. L. (1998), «La elocutio en las Institutionum rhetoricarum de Fadrique Furió Ceriol», en Albadalejo, T. et alii (coords.), Quintiliano, historia y actualidad de la retórica, Logroño, Instituto de Estudios Riojanos - Ayuntamiento de Calahorra, 1998, 1397-1404.

- (1999), Retóricas españolas del siglo XVI: El foco de Valencia, Madrid, Consejo Superior de Investigaciones Científicas, 1999.

Maquiavelo, N. (1983² [1981]), El Príncipe, introducción, traducción y notas de M. A. Granada, Madrid, Alianza Editorial.

- (1987), Discursos sobre la primera década de Tito Livio, introducción, traducción y notas de Ana Martínez Arancón, Madrid, Alianza Editorial.

Martín, A. (1997), «La literatura en los tratados españoles de retórica del siglo XVI», Rhetorica $15.1,1-39$.

Méchoulan, H. - Almenara, M. (1996), «Elementos históricos y cronológicos para una biografía», en Méchoulan, H. - Pérez Durà, J. (eds.), Furió Ceriol, F. Obra completa I. El Concejo y Consejeros del Príncipe. Bononia, Valencia, Edicions Alfons el Magnànim, 13-43.

Merchán, C. (2002), «Pensamiento político-administrativo y doctrina en Furió Ceriol (Valencia, 1527 - Valladolid, 1592)», Anuario de historia del derecho español 72, 544-568.

Merino, L. (1992), La pedagogía en la retórica del Brocense. Los principios pedagógicos del humanismo renacentista (natura, ars y exercitatio) en la retórica del Brocense (memoria, methodus $y$ analysis), Cáceres, Universidad de Extremadura.

Núñez, J. M. (2002), «La doctrina de la elocutio en la retórica española del Renacimiento», en Maestre, J. M. et al. (eds.), Humanismo y pervivencia del mundo clásico, III.2, Alcañíz - Madrid, Instituto de Estudios Humanísticos - Universidad de Cádiz, 667-689.

Puerta, D. (1993), «Fadrique Furió Ceriol: aproximación a su obra retórica», en Maestre, J. M. et al. (eds.), Humanismo y pervivencia del mundo clásico, I.2, Cádiz, Instituto de Estudios Turolenses - Universidad de Cádiz, 851-856.

- (1998), «Algunas consideraciones sobre la retórica de F. Furió Ceriol», SPhV3, 121-134.

Ramus, P. (1550), Petri Rami Veromandui Institutionum Dialecticarum libri tres, Audomari Talaei praelectionibus illustrati, ad Carolum Lotharingum Cardinalem Gü̈sianum. Lutetiae, ex typographia Matthaei Davidis.

Requesens, J. (2009), «D’ètica i de política al segle XVI. Joan Lluís Vives, Frederic Furió i Joan de Borja», Enrahonar 42, 91-128. DOI: https://doi.org/10.5565/rev/enrahonar.287 [23-04-2021]

Real Academia Española (s.f.), ejemplo, en Diccionario de la lengua española, 23. ${ }^{a}$ ed., [versión 23.4 en línea]. <https://dle.rae.es> [09-09-2021]

Talon, O. (1545), Audomari Talaei Veromandui Institutiones Oratoriae, ad celeberrimam et illustrissimam Lutetiae Parisiorum Academiam, Parisiis, excudebat Iacobus Bogardus. 
- (1552), Audomari Talaei Rhetorica ad Carolum Lotharingum Cardinalem. Quinta et postrema aeditio, ex uera et recentiori authoris recognitione. Lutetiae, ex typographia Matthaei Davidis.

Truman, R. W. (2009), «Fadrique Furio Ceriol's Institutionum Rhetoricarum libri tres (Leuven 1554)», en Papy, J. (ed.), Syntagmatia: Essays on Neo-Latin Literature in Honour of Monique Mund-Dopchie and Gilbert Tournoy, Lovaina, University Press, 372-383.

Villacañas, J. L. (2015), «Vidas de estudiantes. Furió Ceriol y la pragmática de 1559», en Ruiz Ibáñez, J. J. - Pérez Tostado, I. (coords.), Los exiliados del rey de España, Madrid, 53-76. 